\title{
Changes in zooplankton communities along a mercury contamination gradient in a coastal lagoon (Ria de Aveiro, Portugal)
}

\author{
Patrícia Gonçalves Cardoso a,*, Sónia Cotrim Marques ${ }^{\mathrm{b}}$, Mariaelena D’Ambrosio ${ }^{\mathrm{a}}$, Eduarda Pereira ${ }^{\mathrm{d}}$, \\ Armando Costa Duarte ${ }^{\mathrm{d}}$, Ulisses Miranda Azeiteiro ${ }^{\mathrm{b}, \mathrm{c}}$, Miguel Ângelo Pardal ${ }^{\mathrm{b}}$ \\ a IMAR - Institute of Marine Research, Department of Life Sciences, University of Coimbra, 3004-517 Coimbra, Portugal \\ ${ }^{\mathrm{b}}$ CFE - Centre for Functional Ecology, Department of Life Sciences, University of Coimbra, P.O. Box 3046, 3001-401 Coimbra, Portugal \\ ${ }^{\mathrm{c}}$ Universidade Aberta, Department of Sciences and Technology, P-4200-055 Oporto, Portugal \\ ${ }^{\mathrm{d}}$ Department of Chemistry and CESAM, University of Aveiro, 3810-193 Aveiro, Portugal
}

\section{A R T I C L E I N F O}

\section{Keywords:}

Mercury

Contamination gradient

Estuaries

Mesozooplankton

Bioaccumulation

\begin{abstract}
A B S T R A C T
The main objective of this paper was to evaluate the impact of mercury on the zooplankton communities' structure and functioning and their bioaccumulation patterns along a contamination gradient in a temperate coastal lagoon. Our results demonstrated that total abundance was not negatively affected by $\mathrm{Hg}$ contamination, since the most contaminated areas presented the highest values, being the copepod Acartia tonsa the dominant species, which means that it is a very well adapted and tolerant species to mercury. Nevertheless, negative effects were observed in terms of species diversity, since the most contaminated areas presented the lowest values of species richness, evenness and heterogeneity. Moreover, the spatial mercury gradient was reflected on the bioaccumulation patterns of the zooplankton communities. This reinforces the idea that zooplankton can be considered as an important vehicle of mercury transfer through the food pelagic web since it constitutes a primordial food resource for several commercial fish species.
\end{abstract}

(C) 2013 Elsevier Ltd. All rights reserved.

\section{Introduction}

Mercury $(\mathrm{Hg})$ is one of the most hazardous contaminants in aquatic environments recognized by the European Water Framework Directive (WFD) as a high priority environmental pollutant. Its high mobility, persistence and lipophilicity (Nunes et al., 2008) may lead to severe widespread environmental problems due to its tendency to bioaccumulate, and toxicity for wildlife and humans (e.g. Coelho et al., 2008; Nfon et al., 2009).

The accumulation of mercury from nonpoint sources and direct discharges from industrial factories in aquatic ecosystems, where local populations extensively use resources, is also a serious conservation and human health concern in coastal areas (Selin, 2009; Costa et al., 2012). Estuaries may constantly receive mercury discharges being sediments repositories of this contaminant, and consequently a potential source of mercury for the aquatic environment (De Marco et al., 2006). In turns, mercury biotransfers up to the food chain via both benthic and pelagic pathways (Coelho et al., 2008; Chen et al., 2009), being the contamination a dangerous risk to the estuarine species most of them representing high ecological and economic interest. Moreover, other risks are

\footnotetext{
* Corresponding author. Tel.: +351 239855760x414; fax: +351 239823603.

E-mail address: gcardoso@ci.uc.pt (P.G. Cardoso).
}

involved, namely, considering edible species, food safety and lastly public health (Karagas et al., 2012).

Recent studies have emphasized the need to address upper and lower trophic levels separately to understand the accumulation and fate of metal contaminants at different trophic levels (Chen et al., 2000). Many zooplankton species can accumulate and metabolize pollutants and then their abundance and/or the species diversity can be used as an indicator of water quality (Telesh, 2004; Thompson et al., 2007; Stewart et al., 2008). In addition, metal accumulated in these organisms has also the potential to provide information about the bioavailability of toxic metals in aquatic systems (Rainbow, 2002). In this respect, previous research has demonstrated that variations in the zooplankton community structure are associated with variations in the concentrations of mercury in fish tissues and therefore may be effective predictors of mercury biomagnification (Chen and Folt, 2005). On the other hand, phytoplankton accumulates mercury (bioconcentration) and together with mercury enriched particles in the water column serve as a food source supporting zooplankton growth (Mason et al., 1995; Wu and Wang, 2011). This leads to important mercury concentrations in planktivorous fish as well as in top predators in pelagicbased food webs (Stewart et al., 2008; Chetelat et al., 2011).

In estuarine coastal waters copepods are usually the dominant group of mesozooplankton (e.g. Kimmel and Roman, 2004; 
Marques et al., 2007) playing important roles in trophic food webs since they are a link between primary producers and secondary consumers. Their role as major grazers in aquatic food webs (Turner, 2004) attribute them a key role in the estuarine planktonic food web and concomitantly in the pelagic food web mercury dynamics. This increase of mercury concentrations through the trophic web (biomagnification) is well documented in literature (Selin, 2009; Costa et al., 2012), particularly in Ria de Aveiro (Portugal) (Coelho et al., 2008; Pereira et al., 2009, and reference therein). However, to our knowledge, there is a scarce literature on the effects of mercury contamination, on the distribution, structure and functioning of zooplankton in European estuaries. The first works in Ria de Aveiro, from Monterroso et al. (2003) and Pereira et al. (2007), concluded that zooplankton is a key component in the biogeochemical cycle of mercury in estuaries, since it can be a transporting agent to other areas of the system or to the open sea. In the present study the zooplankton was monitored as an indicator of possible ecosystem changes resulting from mercury contamination. The main goals of the present work were: (1) to analyze the distribution of the zooplankton assemblages along a mercury gradient and infer about the impact of this contaminant on their structure (density/ biomass and taxonomic groups) and functioning (species diversity), and (2) to analyze the bioaccumulation patterns, highlighting species or groups with higher or lower Hg tolerance. Such knowledge is necessary to fulfill notable data gaps in the literature on mercury in zooplankton in estuarine ecosystems and contribute to the understanding of baseline factors that control mercury uptake and fate in upper trophic levels of estuarine food webs.

\section{Materials and methods}

\subsection{Study site}

The study was conducted in the Ria de Aveiro coastal lagoon, located on the north-west coast of Portugal $\left(40^{\circ} 38^{\prime} \mathrm{N}, 8^{\circ} 45^{\prime} \mathrm{W}\right)$
(Fig. 1). Its topography consists of four main channels, which radiate from the mouth with several branches, islands and mudflats (Fig. 1). Tidal influence is the main factor influencing circulation within the lagoon. The system received, from 1950 to mid 1990s, continuous mercury discharges from a chlor-alkali plant located in Estarreja industrial complex (Pereira et al., 2009). This induced an environmental contamination gradient inside the lagoon, mainly in the Laranjo Bay corresponding to a highly contaminated area located close to the mercury discharge source (Coelho et al., 2008). In the last decades, the mercury discharge decreased considerably due to legal restrictions (e.g. $50 \mu \mathrm{g} \mathrm{Hg} \mathrm{L}^{-1}$ is the limit value for discharges from chlor-alkali plants, in accordance with the European Union Directive 82/176/EEC). However, the mercury accumulated in the sediments of some areas of the Ria is still high posing several risks to the environment and ultimately to humans (Pereira et al., 2009).

Four sampling stations were selected in the Laranjo Bay along a transect defined by the distance from the mercury point source: station 1 (St 1 ) is considered to be at the mercury point source in the lagoon, and the others stations are progressively further from this one, respectively $600 \mathrm{~m}$ (station 2, St 2), $3000 \mathrm{~m}$ (station 3, St 3) and $5000 \mathrm{~m}$ (station 4, St 4) (Fig. 1).

\subsection{Zooplankton and environmental data}

Zooplankton horizontal hauls with a plankton net equipped with $200 \mu \mathrm{m}$ mesh net were conducted in Ria de Aveiro, on a monthly basis, from September 2010 to September 2011. The samples were collected during the day, at flood tide, across the four sampling stations (Fig. 1). A Hydro-Bios flowmeter was used to estimate volume filtered by each haul. After each haul, the net was rinsed and the samples for $\mathrm{Hg}$ determination were immediately frozen while the remaining samples were preserved in $4 \%$ formalin-seawater solution. These were later sub-sampled for numerical abundance using a Folsom plankton splitter. At each subsample a minimum of 500 individuals were counted using a

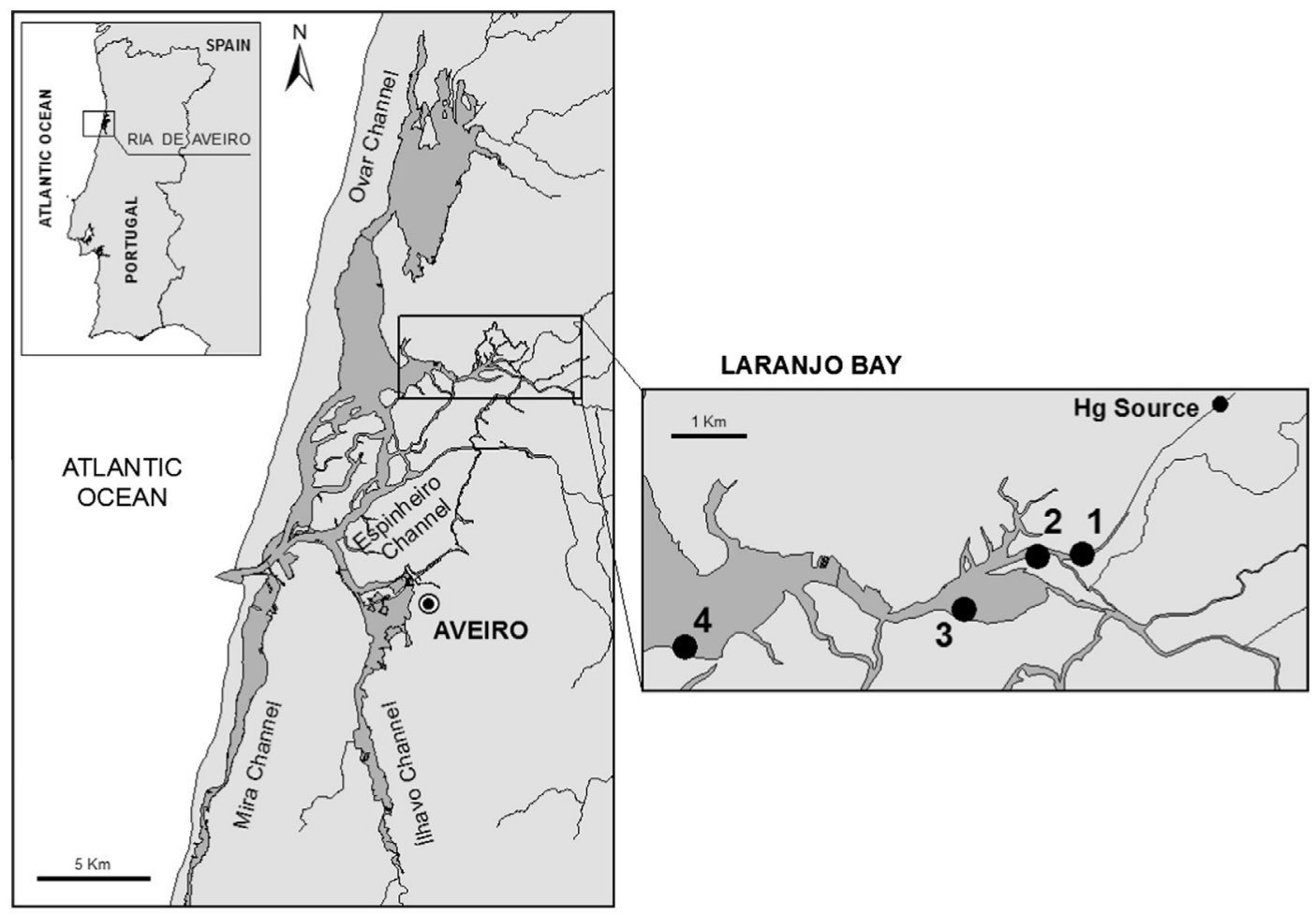

Fig. 1. Overview (left) and detailed map (right) of the study area with location of the sampling stations in Ria de Aveiro. 
Bogorov counting chamber and then identified to the lowest possible taxonomic level (whenever possible organisms were identified to the species level, otherwise to the genera) under a stereoscopic microscope (Leica Led 2500) using the identification keys and reference books by Rose (1933), Tood and Laverack (1991) and Alonso (1996). Densities were calculated and expressed as individuals per cubic meter (ind $\mathrm{m}^{-3}$ ).

Environmental measurements were taken simultaneously with the zooplankton sampling. Water temperature $\left({ }^{\circ} \mathrm{C}\right)$ (probe: CDC401), salinity (probe: CDC401), dissolved oxygen $\left(\mathrm{mg} \mathrm{L}^{-1}\right)$ (probe: LD0101) and pH (probe: pHC281) were measured in situ, at the surface, through a multiparametric probe (Hach Lange HQ30d). Water samples for determination of chlorophyll $a$ (chla, $\mathrm{mg} \mathrm{m}^{-3}$ ), total suspended solids (TSS, $\mathrm{mg} \mathrm{L}^{-1}$ ), total dissolved mercury (ng L ${ }^{-1}$ ), and mercury associated to the suspended particulate matter (SPM, $\mu \mathrm{g} \mathrm{g}^{-1}$ ) were collected. For determination of chlorophyll $a$ (Chl-a), $500-700 \mathrm{~mL}$ water samples were filtered onto Whatman GF/C glassfibre filters followed by extraction following the protocol of Parsons et al., (1985). For the SST quantification it was followed the protocol of APHA (1995).

Sediments from each site were also collected for total mercury content quantification. They were homogenized and freeze-dried for posterior mercury analysis. At the laboratory, water samples were filtered with $0.45 \mu \mathrm{m}$ pore size filters (Millipore), acidified with concentrated $\mathrm{HNO}_{3}$ "mercury free" to $\mathrm{pH}<2$ and maintained at $4{ }^{\circ} \mathrm{C}$ until analysis.

\subsection{Mercury quantifications in sediments, water column and organisms}

For total mercury quantification in organisms and sediments, freeze-dried samples were analyzed by thermal decomposition atomic absorption spectrometry with gold amalgamation, using a LECO AMA-254 (Advanced Mercury Analyzer), with a limit of detection of $0.01 \mathrm{ng}$. Analytical quality control was performed using Certified Reference Materials (CRMs): TORT-2 lobster hepatopancreas (for the organisms), while for the sediments MESS-3 (low contaminated sediments) and PACS-2 (high contaminated sediments) were used. The values obtained for the whole CRM analysis was $120 \%$ for the organisms and $97-103 \%$ (at 0.05 significance level) for the sediments. Analyses of CRMs and samples were always performed in triplicate and coefficient of variation was lower than $10 \%$. Total dissolved mercury analysis was performed by cold-vapor atomic fluorescence spectroscopy (CV-AFS), using a PS model Merlin 10.023 equipped with a detector PSA model 10.003 and using, as reducing agent, $\mathrm{SnCl}_{2}$. This analytical methodology is highly sensitive, allowing the measurement of $1 \mathrm{ng} \mathrm{L}^{-1}$ of mercury (Mucci et al., 1995). For determination of mercury concentrations in SPM, filters (from the previous process of water filtration) were oven-dried at $60^{\circ} \mathrm{C}$ and acid digested with $\mathrm{HNO}_{3} 4 \mathrm{~mol} \mathrm{~L}^{-1}$. After $\mathrm{HNO}_{3}$ digestion, the mercury was analyzed by CV-AFS (Pato et al., 2008).

\section{Data analysis}

\subsection{Environmental variables}

Statistical differences in environmental variables as a function of sampling stations were tested with a one-way analysis of variance (ANOVA). All data were previously checked for normality using the Kolmogorov-Smirnov test and for homogeneity of variances using the Levene's test (Zar, 1996). Data not meeting these criteria were transformed appropriately (Zar, 1996) and checked again for normality and homocedasticity. Whenever data did not meet those criteria, non-parametric tests (Kruskal-Wallis test) were applied. These analyses were performed in the Minitab 16 software package.

\subsection{Zooplankton community}

\subsubsection{Univariate analyses}

Diversity indices (number of species, Pielou's species evenness and Shannon-Wiener diversity) and abundance of zooplankton assemblages were computed for each station (Clarke and Warwick, 2001).

\subsubsection{Multivariate analyses}

A distance-based permutational multivariate analysis of variance (PERMANOVA, Anderson, 2001) was used to test hypotheses about differences in zooplankton assemblages along the contamination gradient, due to the predominance of zeros and the variability between samples. This analysis does not assume normality or any other specified distribution. PERMANOVA model consisted of one factor (station, 4 levels, fixed). The Bray-Curtis similarity coefficient matrix was used as the distance metric with 9999 permutations for the probability tests. Data for species abundance was square-root transformed. When necessary, significant terms of interest were investigated using a posteriori pairwise comparisons.

To visualize multivariate patterns revealed by PERMANOVA, canonical analysis of principal coordinates was applied (CAP, Anderson and Willis, 2003). In this study was used a specific case of CAP (canonical correlation) since the objective was to perceive how well the biotic data (zooplankton community) differentiated the samples along a quantitative mercury gradient. Based on this, it was performed a Principal Components Analysis (PCA) with mercury concentrations (sediment, dissolved and SPM) and selected the single variable with the scores for samples along PC1. This information was used to run the CAP and relate the pollution gradient to the biotic matrix. The abiotic data was previously logtransformed while the biotic matrix was square-root transformed for posterior calculation of Bray-Curtis distances (Anderson et al., 2008).

Finally, RELATE and DISTML (distance-based linear model) routines were performed (Clarke and Gorley, 2006; Anderson et al., 2008) to analyze and model the relationship between the zooplankton assemblages and the environmental variables. The assemblage DISTLM was constructed using the step-wise selection procedure and the adjusted $R^{2}$ as selection criterion to enable the fitting of the best explanatory environmental variables in the model (Anderson et al., 2008). Euclidean distance was used as resemblance measure in all DISTLM procedures. The full set of 9 available environmental variables was tested for collinearity (Draftsman plot and Spearman correlation matrix) and (redundant) variables with correlations $\left(r^{2}\right)>0.7$ were omitted from the model. The environmental variables selected were: salinity, TSS, total dissolved $\mathrm{Hg}, \mathrm{Hg}$ in sediments and chlorophyll $a$. To minimize the seasonal variability monthly anomalies were obtained for each biotic and environmental dataset before calculating the distance matrix. This procedure was only used for the present analysis.

All multivariate and diversity analyses were performed using PRIMER v.6 and its add-on package PERMANOVA+ (Clarke and Warwick, 2001; Clarke and Gorley, 2006; Anderson et al., 2008).

\section{Results}

\subsection{Environmental variables}

Temperature, salinity and chlorophyll $a$ values showed a typical seasonal distribution with lower values during winter (Temp.: $7.7^{\circ} \mathrm{C}$, Sal.: 4.3, Chl- $a$ : $0.99 \mathrm{mg} \mathrm{m}^{-3}$ ) and higher values during 
summer (Temp.: $24.8^{\circ} \mathrm{C}$, Sal.: 37, Chl-a: $16.9 \mathrm{mg} \mathrm{m}^{-3}$ ) (Fig. 2a-c). Total suspended solids (TSS) showed a more irregular pattern (Fig. 2d). Considering the environmental variables no significant differences were observed between the four sampling stations (One-way ANOVA, Temperature: $F_{3}=0.03, P>0.05$; Kruskal-Wallis, Salinity: $\mathrm{H}_{3}=1.30, P>0.05$; Chlorophyll $a$ : $H_{3}=1.21, P>0.05$; TSS: $H_{3}=2.44, P>0.05$ ). The study area was, thus, comparatively uniform with respect to water mass characteristics during the sampling period.

\subsection{Mercury concentrations in sediments, and water column}

Total mercury in sediments varied significantly between all the stations (One-way ANOVA, $F_{3}=323.01, P<0.05$ ). In fact, there is a clear spatial gradient across the different stations, from a maximum at station $1\left(132 \pm 38.9 \mu \mathrm{g} \mathrm{g}^{-1}\right)$, followed by St $2\left(16.4 \pm 4.9 \mu \mathrm{g} \mathrm{g}^{-1}\right)$, St $3\left(1.9 \pm 0.4 \mu \mathrm{g} \mathrm{g}^{-1}\right)$ and St $4\left(1.1 \pm 0.6 \mu \mathrm{g} \mathrm{g}^{-1}\right)$ (Fig. 3 ).

Total dissolved mercury presented lower values during winter (10.1 $\left.\pm 1.6 \mathrm{ng} \mathrm{L}^{-1}\right)$ and spring $\left(17.5 \pm 5.1 \mathrm{ng} \mathrm{L}^{-1}\right)$ and higher concentrations were recorded during the summer $\left(39.2 \pm 27 \mathrm{ng} \mathrm{L}^{-1}\right)$ and autumn $\left(37.9 \pm 7.9 \mathrm{ng} \mathrm{L}^{-1}\right)$. Spatially, station $1\left(29.1 \pm 24 \mathrm{ng} \mathrm{L}^{-1}\right)$ recorded higher mercury concentrations than the other three stations, being St $4\left(20.6 \pm 16.2 \mathrm{ng} \mathrm{L}^{-1}\right)$ the one that registered the lowest mercury concentrations. Nevertheless, no significant difference was observed between sampling stations (Kruskal-Wallis, $\left.\mathrm{H}_{3}=2.43, P>0.05\right)$. In the SPM fraction, the existence of a mercury spatial gradient was verified, especially during summer and autumn with St 1 and 2 presenting the highest values. Significant differences were observed between St 1 and 3, St 1 and 4 , and St 2 and 4 (One-way ANOVA, $F_{3}=5.57, P<0.05$ ).

\subsection{Zooplankton community structure and diversity}

Differences in zooplankton community structure were observed throughout the contamination gradient. Slightly higher abundances were recorded at upstream and more contaminated section of the Laranjo Bay (St 1 and 2, average $3309 \pm 3867.8$ and $4701.3 \pm 4483.9$ ind $\mathrm{m}^{-3}$, respectively), whereas lower values were recorded at St 3 and 4 (average 2772.1 \pm 2675 and $1492.96 \pm 1115.8$ ind $\mathrm{m}^{-3}$, respectively). However, no significant differences were observed between them (One-way ANOVA, $\left.F_{3}=0.79, P>0.05\right)$. Total zooplankton abundance peaks occurred
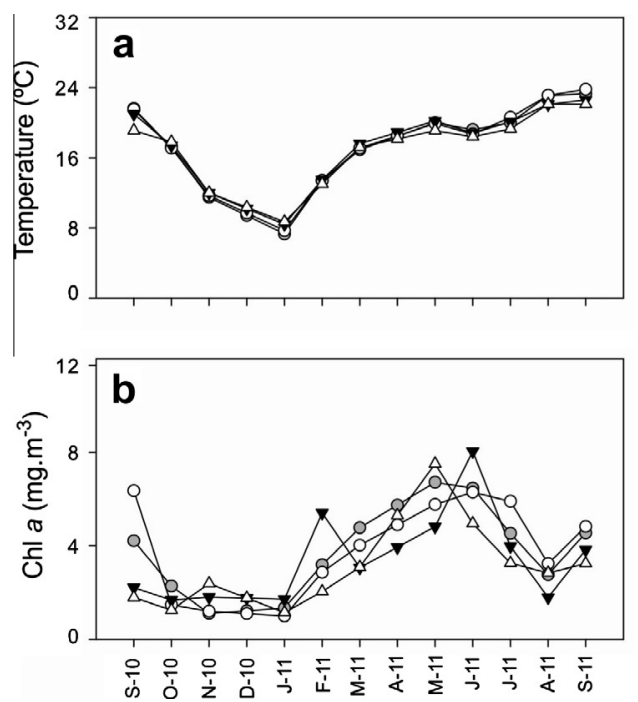
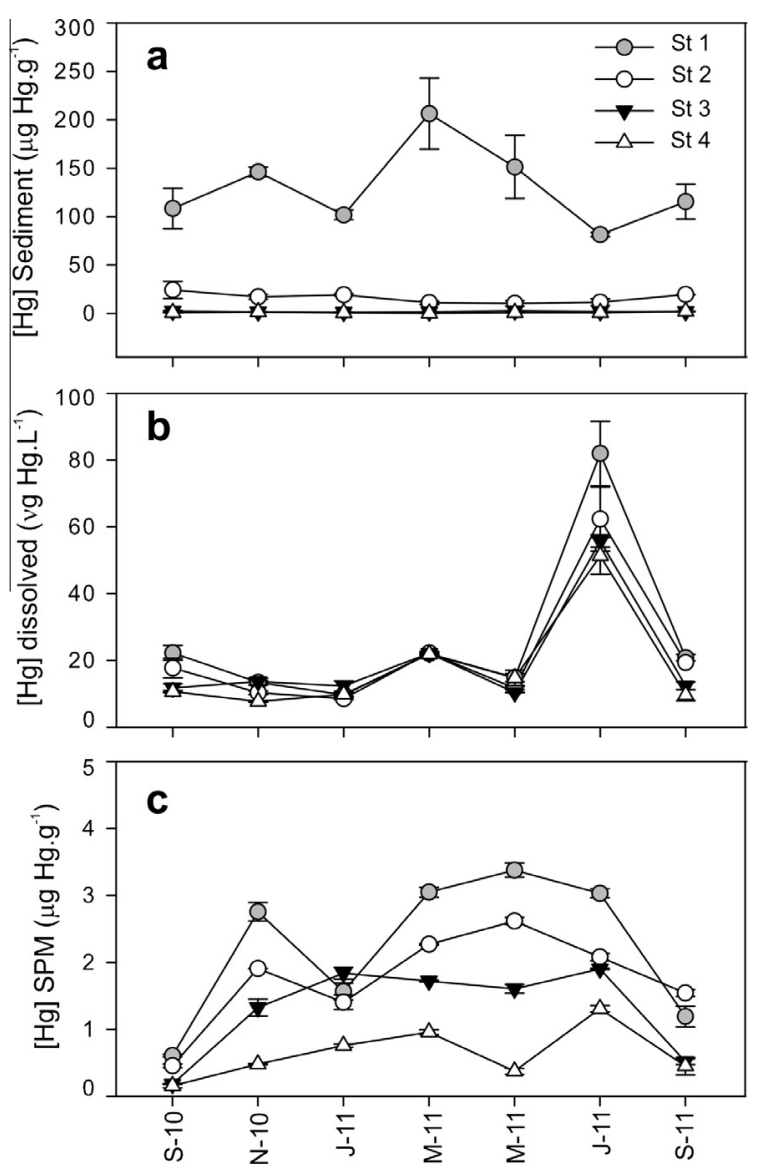

Fig. 3. Total mercury levels in sediments $\left(\mu \mathrm{g} \mathrm{g}^{-1}\right)$, dissolved fraction $\left(\mathrm{ng} \mathrm{L}^{-1}\right)$ and associated to the suspended particulate matter $\left(\mu \mathrm{g} \mathrm{g}^{-1}\right.$ ) (error bars indicate standard deviation, $n=11$ ).

during summer/autumn and showed a consistent decrease in winter (Fig. 4a).

The spatial and seasonal distribution of the main taxonomic groups showed that the copepods were consistently the dominant group, namely the estuarine resident species (94.6-66.7\%), Acartia
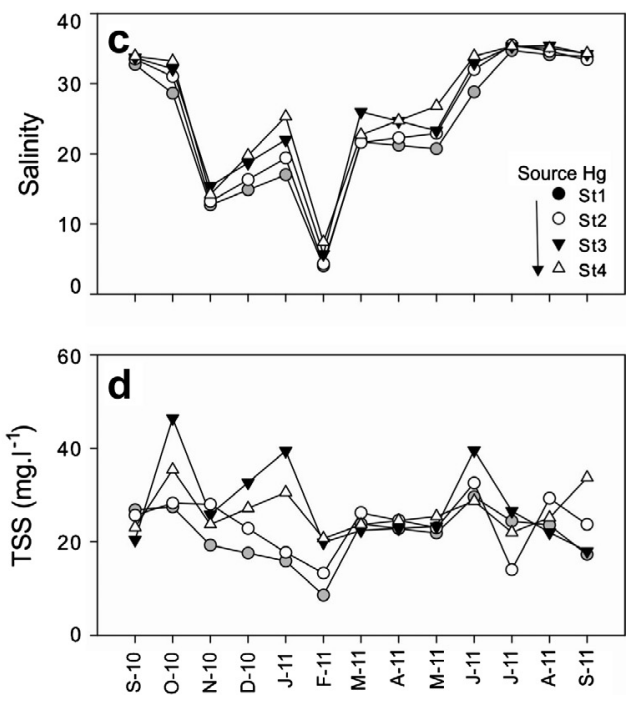

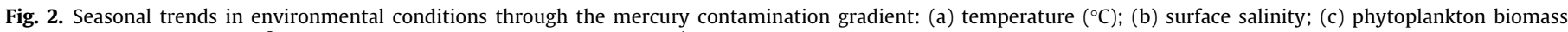
(chlorophyll a, Chl- $a, \mathrm{mg} \mathrm{m}^{-3}$ ); and (d) total suspended solids (TSS, mg.l ${ }^{-1}$ ). 

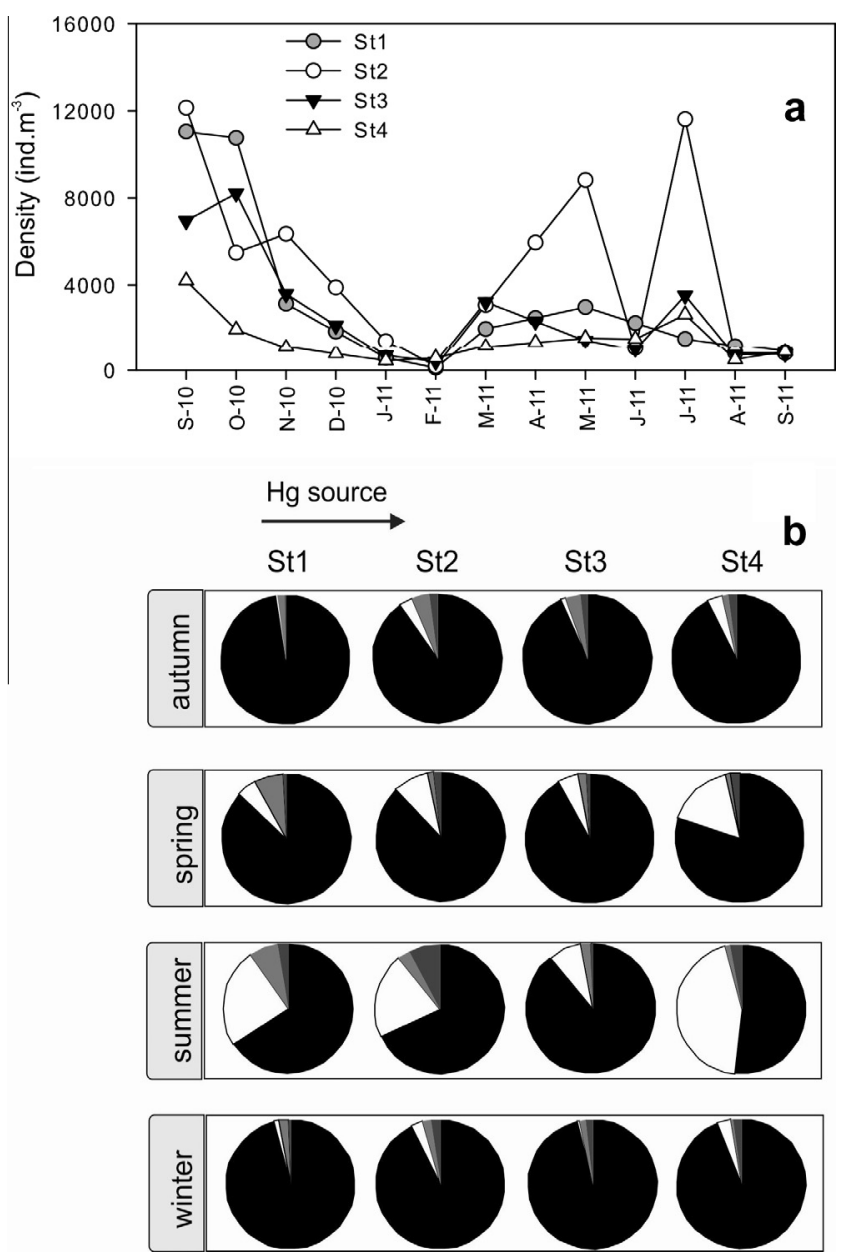

Estuarine copepods

Others

Marine copepods

Cladocerans

Fig. 4. Seasonal trends in zooplankton: (a) Zooplankton density (ind $\mathrm{m}^{-3}$ ); and (b) proportional contribution of major zooplankton taxonomic groups (estuarine copepods, black; marine copepods, white; cladocerans, light grey; others, dark grey) to total zooplankton density based on season means.

tonsa. Next, appear the marine copepods (23.9-2.2\%), with greater representation at St4 (Fig. 4b). Other taxa such as Cladocera, Appendicularia and Cirripedia occurred typically in lower abundance $(<3 \%)$.

Regarding species richness, a significant increase from the most contaminated area to the least contaminated one was observed (St $1-12 \pm 3.8$ species, St $4-22 \pm 6.0$ species) (One-way ANOVA, $F_{3}=12.56, P<0.05$ ) (Fig. 5a). A similar pattern was found for zooplankton evenness (St $1-0.39 \pm 0.1$, St $4-0.57 \pm 0.1$ ) and heterogeneity (St $1-1.4 \pm 0.5$, St $4-2.6 \pm 0.7$ ) with significant differences between extreme areas (One-way ANOVA: evenness, $F_{3}=8.9$, $P<0.05$; heterogeneity, $F_{3}=13.2, P<0.05$ ) (Fig. $5 \mathrm{~b}$ and $\mathrm{c}$ ). In summary, stations further away from the contamination source were more diverse and equitable, whilst the stations close to the mercury discharge harbored less diverse and more even communities.

\subsection{Multivariate analysis}

The PERMANOVA analysis showed significant differences in zooplankton assemblages between stations 1 and 3, 1 and 4 and between stations 2 and $4(P<0.01$, Table 1$)$. This was further confirmed by the CAP analysis which demonstrated a strong relationship between changes in zooplankton community structure and
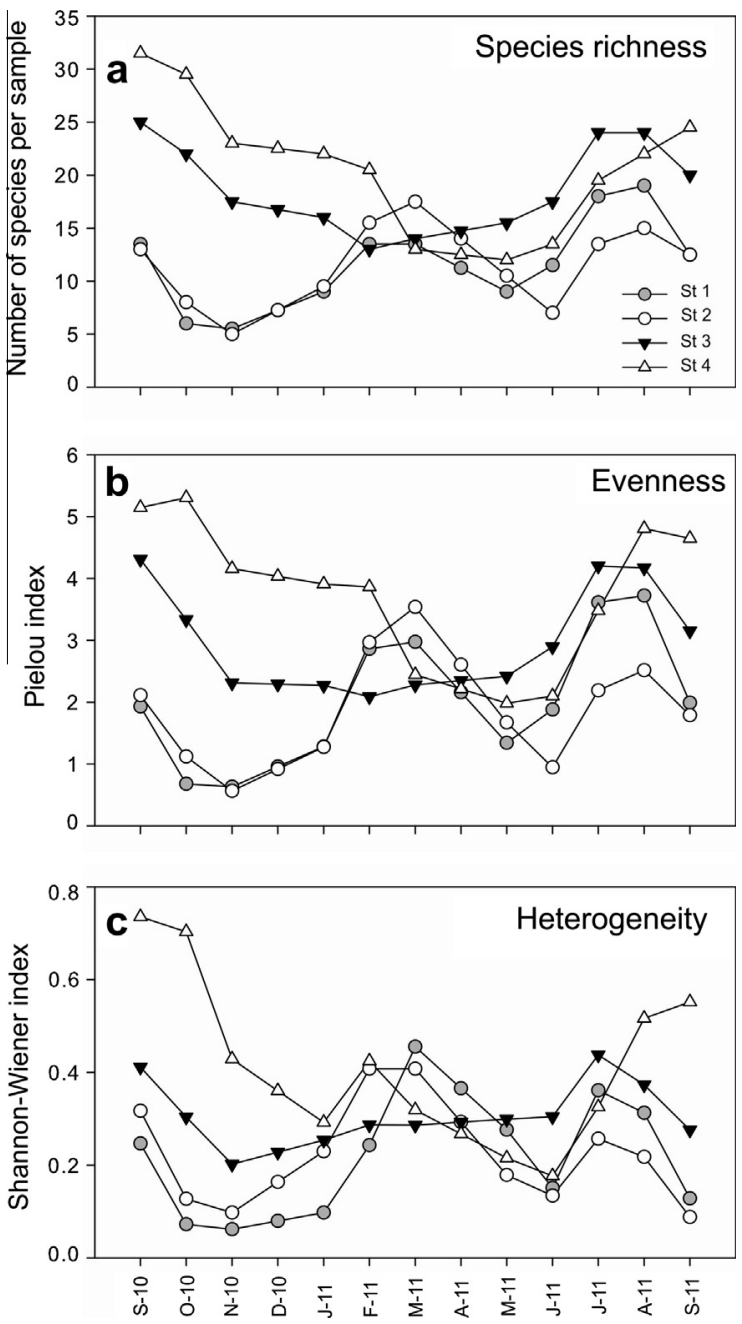

Fig. 5. Changes in zooplankton: (a) species richness; (b) evenness and (c) Shannon Wiener diversity (Heterogeneity) at each sampling station over the study period.

the environmental gradient of mercury content with a canonical correlation (using $m=8$ principal coordinate axes) of $\delta^{2}=0.80$ (Fig. 6). The CAP analysis showed a clear discrimination between samples from the 4 stations.

Comparison between zooplankton abundance and environmental similarity matrices showed a medium significant correlation (RELATE, $r=0.46, P=0.001$ ). The DISTLM analysis revealed that total dissolved $\mathrm{Hg}$, Chl- $a$ and $\mathrm{Hg}$ in sediments had significant influences on the structure of the zooplankton assemblages. The best fitted model, based on the retained environmental variables that explained the zooplankton assemblages is shown in Table 2. These results show that total dissolved $\mathrm{Hg}$ accounted for $29 \%$ of the variance observed. Other main contributors include Chl- $a$ (21\%) and $\mathrm{Hg}$ in sediments (13\%). The influence of total dissolved $\mathrm{Hg}$ remained significant in sequential tests after the effect of Chl- $a$ was taken into account, but $\mathrm{Hg}$ in sediments was no longer significantly correlated with zooplankton abundance.

\subsection{Mercury bioaccumulation in the zooplankton}

The results indicated a clear mercury bioaccumulation throughout the spatial gradient, with higher values at St 1 $\left(0.1 \pm 0.02 \mu \mathrm{g} \mathrm{g}^{-1}\right)$ and lower values at St $4\left(0.01 \pm 0.002 \mu \mathrm{g} \mathrm{g}^{-1}\right)$ (Fig. 7). Overall significant differences between sampling stations 
Table 1

Summary of results of permutational multivariate analysis of variance (PERMANOVA) and post hoc pairwise comparisons of zooplankton assemblages at 4 sampling stations.

\begin{tabular}{lcclll}
\hline Source of variation & df & SS & MS & $F$ & $P$ \\
\hline Station (St) & 3 & 9458.2 & 3152.7 & 1.787 & 0.0084 \\
Pairwise post hoc comparisons & of stations & & \\
\hline Groups & $t$ & & $P$ \\
\hline 1,2 & 0.765 & & 0.804 \\
1,3 & 1.345 & & $\mathbf{0 . 0 4 5}$ \\
1,4 & 1.851 & & $\mathbf{0 . 0 0 2}$ \\
2,3 & 1.005 & & 0.434 \\
2,4 & 1.636 & $\mathbf{0 . 0 0 9}$ \\
3,4 & 1.078 & & 0.311 \\
\hline
\end{tabular}

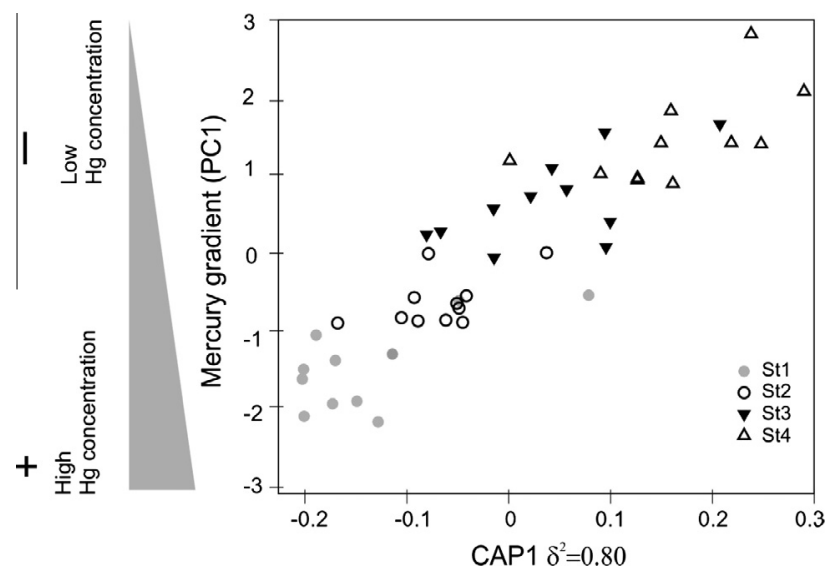

Fig. 6. Canonical analysis of principal coordinate (CAP1) vs PC1 scores of $\mathrm{Hg}$ (obtained from PCA). $\delta^{2}$ : square canonical correlation.

Table 2

Result of distance-based linear model (DistLM). Results of the marginal tests show the influence of each parameter in isolation, whereas results of the sequential tests show the effect of environmental parameters on zooplankton assemblages in the combined model (stepwise selection with adjusted $R^{2}\left[R_{\mathrm{adj}}^{2}\right]$ criterion).

\begin{tabular}{lccc}
\hline Variable & SS (trace) & Pseudo- $F$ & Prop. \\
\hline Marginal tests & & & \\
Sal & $3.45 \times 10^{6}$ & 0.38 & 0.01 \\
TSS & $1.30 \times 10^{7}$ & 1.49 & 0.03 \\
Hg Diss.* & $1.11 \times 10^{8}$ & 17.26 & 0.29 \\
Hg sed. & $5.13 \times 10^{7}$ & 6.51 & 0.13 \\
Chl- $a^{* *}$ & $8.14 \times 10^{7}$ & 11.38 & 0.21 \\
Sequential tests & & & \\
Hg Diss & & 17.26 & 0.29 \\
+Chl- $a$ & $1.11 \times 10^{8}$ & 5.41 & 0.08 \\
+ Hg sed. & $3.15 \times 10^{7}$ & 1.07 & 0.02 \\
\hline
\end{tabular}

$\mathrm{Hg}$ sed: total mercury in sediments $\left(\mu \mathrm{g} \mathrm{g}^{-1}\right)$; $\mathrm{Hg}$ diss: total dissolved mercury (ng l-1); Sal: salinity; Chla: chlorophyll $a\left(\mathrm{mg} \mathrm{m}^{-3}\right)$; TSS: total suspended solids $\left(\mathrm{mg} \mathrm{m}^{-3}\right)$. Prop.: proportion of total variation explained; Prop (cumul.): Prop. cumulative.

${ }^{*} P<0.05$.

** $P<0.01$.

were observed (One-way ANOVA, $F_{3}=16.48, P<0.05$ ), except between St 2 and 3.

\section{Discussion}

In the last years, due to the implementation of the Water Framework Directive, there is a great concern with the environmental quality of global aquatic systems with special attention to

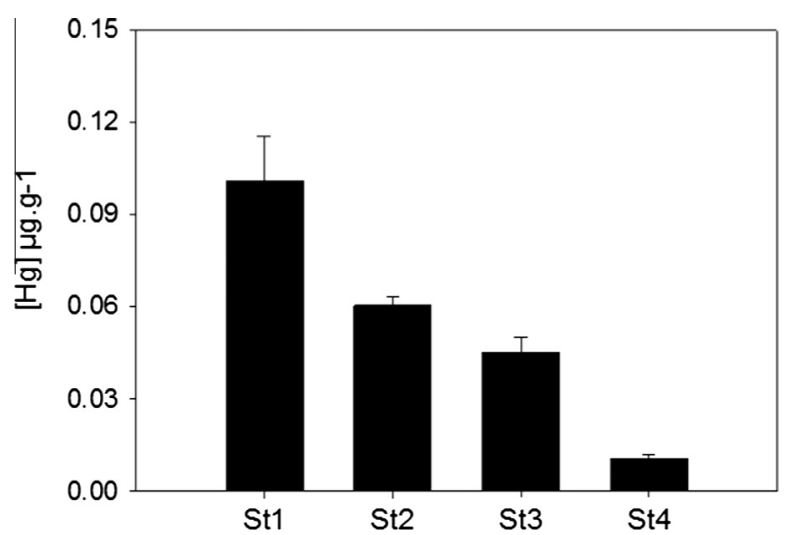

Fig. 7. Total mercury levels ( $\mu \mathrm{g} \mathrm{g}^{-1}$ wet weight) in zooplankton (error bars indicate standard errors).

their ecological condition. Studies on the impact of contaminants, like mercury, in marine ecosystems are of extreme importance, due to its high toxicity and since marine food webs are important links between mercury in the environment and human exposure via consumption of fish (Chen et al., 2012; Oken et al., 2012). Biomonitoring is well known as an effective tool for the assessment of metal pollution in aquatic ecosystem (Zhou et al., 2008) and zooplankton is considered as a good indicator of energy flux in the marine food chain. Although considerable attention has been given to the mercury contamination problems, mercury accumulation in zooplankton has received little attention compared to other biotic groups, like macrobenthos (Raftopoulou and Dimiatris, 2011; Cardoso et al., 2013a), fishes (Abreu et al., 2000; Gehringer et al., 2013), salt marsh vegetation (Válega et al., 2008) and macroalgae (Coelho et al., 2005). Regarding zooplankton, previous work addressed the amount of mercury associated with micro and mesozooplankton exported from Laranjo Bay to the rest of the lagoon (Monterroso et al., 2003) and seasonal mercury accumulation in material collected with plankton nets (63 and $200 \mu \mathrm{m}$ ) (Pereira et al., 2007). The novelty of this study focuses on the impact of mercury and its bioaccumulation patterns on the zooplankton community structure and functioning along a human-induced mercury environmental gradient.

Our findings confirmed a clear mercury spatial gradient that was reflected in the zooplankton mercury bioaccumulation pattern. As expected, $\mathrm{Hg}$ concentration was generally higher at upstream areas, closer to the contamination point source. Zooplankton has the ability to accumulate both inorganic and organic forms of mercury from ingested food and/or directly from the dissolved phase (Wang and Fisher, 1999), which may explain the mercury concentrations and bioaccumulation pattern. In both cases, the contaminants may be assimilated and passed up to higher food levels via trophic transfer or they may be eliminated in fecal pellets (McManus et al., 1983).

Interestingly, the highest abundances were found, generally, in the upstream section of the Laranjo Bay with peaks occurring in spring, summer and autumn months. This seasonal effect in zooplankton abundance was previously reported in other temperate estuaries (e.g. Tackx et al., 2004; David et al., 2007; Marques et al., 2007) and for Canal de Mira, Ria de Aveiro (Leandro et al., 2013). This density pattern seems to follow the chlorophyll $a$ biomass trends resulting from the phytoplankton ecological preferences (Resende et al., 2005; Pereira et al., 2010). Chlorophyll $a$ is an important food resource for the zooplankton as it was evidenced by the DISTLM analyses and at the same time is a relevant element in the $\mathrm{Hg}$ transference through the trophic web. In addition, the spatial and seasonal distribution of the main taxonomic groups shows that the copepods were always the dominant group, namely 
the estuarine resident species, A.tonsa, contributing with more than $90 \%$ of total zooplankton abundance in the most contaminated areas, indicating that is a tolerant species to mercury. Planktonic copepods are important components of marine pelagic food webs, especially in rich productive estuaries of coastal regions (Kimmel and Roman, 2004; David et al., 2007; Marques et al., 2011). The great abundance of estuarine copepods, represented by $A$. tonsa, in the most contaminated areas corroborates the association of this species with polluted environments (Soetaert and Van Rijswijk, 1993; Uriarte and Villate, 2004). Hook and Fisher (2001) determined the effect of exposure route on metal (Cd and $\mathrm{Hg}$ ) accumulation, tissue distribution, and toxicity in A. tonsa. The concentrations tested were at environmentally realistic levels such as those that occur in urbanized estuaries. They exposed adults to food that had been exposed to metals and also dissolved metals in the water. They found that exposure to contaminated food $\left(28 \mathrm{nmol} \mathrm{Hg} \mathrm{g}^{-1}\right)$ resulted in assimilation of the metals primarily into internal tissues affecting vitellogenesis and egg production (decrease 50\%). However, when animals were exposed to dissolved $\mathrm{Hg}$ (concentration $\geqslant 0.25 \mathrm{nM} \mathrm{Hg} 50 \mathrm{ng} \mathrm{Hg}$ ) a decrease on egg production was verified but mortality was observed only with concentrations $\geqslant 300 \mathrm{nM} \mathrm{Hg}(60,000 \mathrm{ng} \mathrm{Hg})$. Our values for total dissolved $\mathrm{Hg}$ were much lower (except in summer that reached $70 \mathrm{ng} \mathrm{L}^{-1}$ ) than the ones used in that experiment which explains the strong permanence of this copepod in the Laranjo Bay. Also, as stated by Bijlsma and Loeschcke (2005) metal tolerance can be based on genotypic adaptation as a result of the selection pressure exerted by a trans-generational exposure history of natural populations. Accordingly, the results suggested that there was probably wide genetic variability within $A$. tonsa species in tolerance to mercury contamination, leading to locally adapted ecotypes displaying an elevated tolerance to metal toxicity (Sørensen et al., 2003).

Further, higher species richness was observed in downstream areas, more noticeable in summer and autumn contributing to the highest diversity observed. The diversity patterns may be related with the contamination gradient. The low species richness recorded in the Laranjo Bay, mainly in the most contaminated areas is clearly associated to the mercury contamination and its adverse effects, as already observed for the suprabenthos (Cardoso et al., 2013b) and also for the macrobenthic communities. Comparing our study site with others, this system is much more impoverished than for example the Mondego estuary (Marques et al., 2007), the Scheldt estuary (Tackx et al., 2004) or the Bahia Blanca estuary (Hoffmeyer, 2004).

Our findings were corroborated by DISTLM and CAP analyses. The first one revealed that the environmental variable with greatest influence on the structure of zooplankton assemblages was total dissolved $\mathrm{Hg}$. This result is contrary to previous studies (Pereira et al., 2007) whose results indicated that zooplankton abundance is not affected by mercury contamination, but rather by parameters such as salinity and temperature. In estuaries, it is not always possible to distinguish the effects of pollution from those of the salinity gradient (Wilson and Elkaim, 1992) on zooplankton distributions. However, in our study the sampling strategy was considered appropriate since the main abiotic variables (salinity and temperature) which can add to the pollution effect in estuaries (Wilson and Elkaim, 1992) showed no significant differences along the study area. In addition, the CAP analysis also identified a strong correlation between the mercury gradient and the zooplankton assemblages, revealing a great discrimination between sampling stations.

In conclusion, the present paper reinforces the importance of zooplankton as valuable indicator of the ecosystem disturbance state highlighting his role as a vehicle of mercury transfer throughout the food web, since the zooplankton is a food resource for the higher trophic levels. Also, the distance from the mercury source was a strong and predictable determinant factor of zooplankton assemblage structure. Therefore, this study constitutes a necessary basis for the understanding of mercury transfer processes within estuarine food webs and their impact on the ecosystem functioning.

\section{Acknowledgments}

This work was supported by FCT (Fundação para a Ciência e Tecnologia) through a project (MERCOAST) - PTDC/MAR/10916/ 2008 and by POPH and QREN - Promotion of Scientific Job funded by European Social Fund and National funds of MEC. SC Marques is a Postdoctoral Fellow of the FCT (SFRH/BPD/65541/2009).The authors are indebted to all the colleagues that assisted in the field and lab work.

\section{References}

Abreu, S., Pereira, E., Vale, C., Duarte, A., 2000. Accumulation of mercury in sea bass from a contaminated Lagoon (Ria de Aveiro, Portugal). Marine Pollution Bulletin 40, 293-297.

Alonso, M., 1996. Crustacea, Branchiopoda. In: Ramos, M.A. et al. (Eds.), Fauna Ibérica, vol. 7. Museo Nacional de Ciencias Naturales. CSIC, Madrid, p. 486 pp.

Anderson, M.J., 2001. Permutation tests for univariate or multivariate analysis of variance and regression. Canadian Journal of Fisheries and Aquatic Sciences 58, 626-639.

Anderson, M.J., Willis, T.J., 2003. Canonical analysis of principal coordinates: a useful method of constrained ordination for ecology. Ecology 84, 511-524.

Anderson, M.J., Gorley, R.N., Clarke, K.R., 2008. PERMANOVA+ for PRIMER: guide to software and statistical methods. PRIMER-E, Plymouth.

APHA, 1995. Standard Methods for the Examination of Water and Wastewater, 19th ed. American Public Health Association.

Bijlsma, R., Loeschcke, V., 2005. Environmental stress, adaptation and evolution: an overview. Journal of Evolutionary Biology 18 (4), 744-749.

Cardoso, P.G., Grilo, T.F., Pereira, E., Duarte, A.C., Pardal, M.A., 2013a. Mercury bioaccumulation and decontamination kinetics in the edible cockle Cerastoderma edule. Chemosphere 90, 1854-1859.

Cardoso, P.G., D’Ambrosio, M., Marques, S.C., Azeiteiro, U.M., Coelho, J.P., Pereira, E. 2013b. The effects of mercury on the dynamics of the peracarida community in a temperate coastal lagoon (Ria de Aveiro, Portugal). Marine Pollution Bulletin $72,188-196$.

Chen, C.Y., Folt, C.L., 2005. High plankton densities reduce mercury biomagnification. Environmental Science and Technology 39, 115-121.

Chen, C.Y., Stemberger, R.S., Klaue, B., Blum, J.D., Pickhardt, P.C., Folt, C.L., 2000 Accumulation of heavy metals in food web components across a gradient of lakes. Limnology and Oceanography 45 (7), 1525-1536.

Chen, C.Y., Dionne, M., Mayes, B.M., Ward, D.M., Sturup, S., Jackson, B.P., 2009 Mercury bioavailability and bioaccumulation in estuarine food webs in the Gulf of Maine. Environmental Science and Technology 43 (6), 1804-1810.

Chen, C.Y., Driscoll, C.T., Lambert, K.F., Mason, R.P., Rardin, L.R., Serrell, N., Sunderland, E.M., 2012. Marine mercury fate: from sources to seafood consumers. Environmental Research 19, 1-2.

Chetelat, J., Amyot, M., Garcia, E., 2011. Habitat-specific bioaccumulation of methylmercury in invertebrates of small mid-latitude lakes in North America. Environmental Pollution 159, 10-17.

Clarke, K.R., Gorley, R.N., 2006. PRIMER v6: User Manual/Tutorial. PRIMER-E, Plymouth.

Clarke, K.R., Warwick, R.M., 2001. Change in Marine Communities. An Approach to Statistical Analysis and Interpretation, 2nd ed. Primer-E Ltd., Plymouth.

Coelho, J.P., Pereira, M.E., Duarte, A., Pardal, M.A., 2005. Macroalgae response to a mercury contamination gradient in a temperate coastal lagoon (Ria de Aveiro, Portugal). Estuarine, Coastal and Shelf Science 65, 492-500.

Coelho, J.P., Nunes, M., Dolbeth, M., Pereira, M.E., Duarte, A.C., Pardal, M.A., 2008 The role of two sediment dwelling invertebrates on the mercury transfer from sediments to the estuarine trophic web. Estuarine, Coastal and Shelf Science 78 516-523.

Costa, M.F., Landing, W., Kehrig, H.A., Barletta, M., Holmes, C., Barrocas, P., Evers, D.C., Buck, D., Vasconcellos, A.C., Hacon, S., Moreira, J.C., Malm, O., 2012 Mercury in tropical and sub-tropical coastal environments. Environmental Research 119, 88-100.

Directive $82 / 176 /$ EEC on limit values and quality objectives for mercury discharges by the chlor-alkali electrolysis industry. - 22 March 1982.

David, V., Sautour, B., Chardy, P., 2007. Successful colonization of the calanoid copepod Acartia tonsa in the oligo-mesohaline area of the Gironde estuary (SW France) - natural or anthropogenic forcing? Estuarine, Coastal and Shelf Science $71,429-442$.

De Marco, S.G., Botté, S.E., Marcovecchio, J.E., 2006. Mercury distribution in abiotic and biological compartments within several estuarine systems from Argentina: 1980-2005 period. Chemosphere 65, 213-223. 
Gehringer, D.B., Finkelstein, M.E., Coale, K.H., Stephenson, M., Geller, J.B., 2013. Assessing mercury exposure and biomarkers in largemouth bass (Micropterus Salmoides) from a contaminated river system in California. Archives of Environmental Contamination and Toxicology 64, 484-493.

Hoffmeyer, M.S., 2004. Decadal change in zooplankton seasonal succession in the Bahia Blanca estuary, Argentina, following introduction of two zooplankton species. Journal of Plankton Research 26, 181-189.

Hook, S.E., Fisher, N.S., 2001. Reproductive toxicity of metals in calanoid copepods. Marine Biology 138, 1131-1140.

Karagas, M.R., Choi, A., Oken, E., Horvat, M., Schoeny, R., Kamai, E., Cowell, W., Grandjean, P., Korrick, S., 2012. Evidence on the human health effects of low level methylmercury exposure. Environmental Health Perspectives 120, 799 806.

Kimmel, D.G., Roman, M.R., 2004. Long-term trends in mesozooplankton abundance in Chesapeake Bay USA: influence of freshwater input. Marine Ecology Progress Series 267, 71-83.

Leandro, S.M., Tiselius, P., Queiroga, H., 2013. Spatial and temporal scales of environmental forcing of Acartia populations (Copepoda: Calanoida) in the Canal de Mira (Ria de Aveiro, Portugal). ICES Journal of Marine Science. http:// dx.doi.org/10.1093/icesjms/fst008.

Marques, S.C., Pardal, M.A., Pereira, M.J., Gonçalves, F., Marques, J.C., Azeiteiro, U.M. 2007. Zooplankton distribution and dynamics in a temperate shallow estuary. Hydrobiologia 587 (1), 213-223.

Marques, S.C., Pardal, M.A., Mendes, S., Azeiteiro, U.M., 2011. Using multitable techniques for assessing the temporal variability of species-environment relationship in a copepod community from a temperate estuarine ecosystem. Journal of Experimental Marine Biology and Ecology 405, 59-67.

Mason, R.P., Reinfelder, J.R., Morel, M.M., 1995. Bioaccumulation of mercury and methylmercury. Water, Air and Soil Pollution 80 (1-4), 915-921.

McManus, G.B., Wyman, K.D., Peterson, W.T., Wurster, C.F., 1983. Factors affecting the elimination of PCBs in the marine copepod Acartia tonsa. Estuarine Coasta and Shelf Science 17, 421-430.

Monterroso, P., Abreu, S.N., Pereira, E., Vale, C., Duarte, A.C., 2003. Estimation of Cu, $\mathrm{Cd}$ and $\mathrm{Hg}$ transported by plankton from a contaminated area (Ria de Aveiro). Acta Oecologica 24, 351-357.

Mucci, A., Lucotte, M., Montgomery, S., Plourde, Y., Pichet, P., Tra, H.V., 1995. Mercury remobilization from flooded soils in a hydroelectric reservoir of northern Quebec, La Grande-2: results of a soil resuspension experiment Canadian Journal of Fisheries and Aquatic Sciences 52, 2507-2517.

Nfon, E., Cousins, I.T., Järvinen, O., Mukherjee, A.B., Verta, M., Broman, D., 2009. Trophodynamics of mercury and other trace elements in a pelagic food chain from the Baltic Sea. Science of Total Environment 407 (24), 6267-6274.

Nunes, M., Coelho, J.P., Cardoso, P.G., Pereira, M.E., Duarte, A.C., Pardal, M.A., 2008 The macrobenthic community along a mercury contamination in a temperate estuarine system (Ria de Aveiro, Portugal). Science of Total Environment 405, $186-194$.

Oken, E., Choi, A.L., Karagas, M.R., Mariën, K., Rheinberger, C.M., Schoeny, R., Sunderland, E., Korrick, S., 2012. Which fish should I eat? Perspectives influencing fish consumption choices. Environmental Health Perspectives 120, $790-798$.

Parsons, T.R., Maita, Y., Lally, C.M., 1985. Pigments. In: A Manual of Chemical and Biological Methods for Seawater Analysis. Pergamon Press, Oxford, pp. 101 104.

Pato, P.. Lopes, C., Válega, M., Lillebø, A.I., Dias, J.M., Pereira, E., Duarte, A., 2008. Mercury fluxes between a coastal lagoon (Ria de Aveiro, Portugal) and the Atlantic Ocean. Estuarine, Coastal and Shelf Science 76, 787-796.

Pereira, M.E., Abreu, S., Pato, P., Coelho, J.P., Azeiteiro, U.M., Pardal, M.A., Duarte A.C., 2007. Seasonal mercury concentrations in plankton-net material from contaminated coastal lagoon (Ria de Aveiro, Portugal). Fresenius Environmental Bulletin 16, 1442-1450.

Pereira, M.E., Lillebø, A.I., Pato, P., Válega, M., Coelho, J.P., Lopes, C.B., Rodrigues, S., Cachada, A., Otero, M., Pardal, M.A., Duarte, A.C., 2009. Mercury pollution in Ria de Aveiro (Portugal): a review of the system assessment. Environmental Monitoring Assessment 155, 39-49.

Pereira, C., Azeiteiro, U.M., Pereira, M.J., 2010. Diatoms and dinoflagellates of the outer Aveiro Estuary, Portugal: annual variation and ecology. Fresenius Environmental Bulletin 19 (4a), 704-716.

Raftopoulou, E.K., Dimiatris, V.K., 2011. Comparative study of the accumulation and decontamination of $\mathrm{Cu}$ (essential metal) and $\mathrm{Hg}$ (nonessential metal) in the digestive gland and gills of mussels Mytilus galloprovincialis, using analytical and histochemical techniques. Chemosphere 83, 1155-1165.

Rainbow, P.S., 2002. Trace metal concentrations in aquatic invertebrates: why and so what? Environmental Pollution 120, 497-507.

Resende, P., Azeiteiro, U.M., Pereira, M.J., 2005. Diatom ecological preferences in a temperate shallow estuary (Ria de Aveiro, Western Portugal). Hydrobiologia 544, 77-88.

Rose, M., 1933. Faune de France. Copépodes pélagique. Ed. Féderation Française des Societés de Sciences naturelle, Paris, 374 pp.

Selin, N.E., 2009. Global biogeochemical cycling of mercury: a review. Annual Review of Environment and Resources 34, 43-63.

Soetaert, K., Van Rijswijk, P. 1993. Spatial and temporal patterns of the zooplankton in the Westerschelde estuary. Marine Ecology Progress Series 97, 47-59.

Sørensen, J.G., Kristensen, T.N., Loeschcke, V., 2003. The evolutionary and ecological role of heat shock proteins. Ecological Letters 6, 1025-1037.

Stewart, A.R., Saiki, M.K., Kuwabara, J.S., Alpers, C.N., Marvin-DiPasquale, M., Krabbenhoft, D.P., 2008. Influence of plankton mercury dynamics and trophic pathways on mercury concentrations of top predator fish of a mining-impacted reservoir. Canadian Journal of Fish and Aquatic Sciences 65, 2351-2366.

Tackx, M.L., Nathalie, D.P., Riet, V.M., Azémar, F., Hannouti, A., Damme, S., Fiers, F., Daro, N., Meire, P., 2004. Zooplankton in the Schelde estuary, Belgium and the Nederlands. Spatial and temporal pattern. Journal of Plankton Research 26, 133-141.

Telesh, I.V., 2004. Plankton of the Baltic estuarine ecosystems with emphasis on Neva estuary: a review of present knowledge and research perspectives. Marine Pollution Bulletin 49, 206-219.

Thompson, B., Adelsbach, T., Brown, C., Hunt, J., Kuwabara, J., Neale, J., Ohlendorf, H., Schwarzbach, S., Spies, R., Taberski, K., 2007. Biological effects of anthropogenic contaminants in the San Francisco Estuary. Environmental Research 105, 156 174.

Tood, C.D., Laverack, M.S., 1991. Coastal and Marine Zooplankton (a practical manual for students). Cambridge University Press, 106 pp.

Turner, J.T., 2004. The importance of small planktonic copepods and their roles in pelagic marine food webs. Zoological Studies 43 (2), 255-266.

Uriarte, I., Villate, F., 2004. Effects of pollution on zooplankton abundance and distribution in two estuaries of the Basque coast (Bay of Biscay). Marine Pollution Bulletin 49, 220-228.

Válega, M., Lillebø, A.I., Pereira, M.E., Duarte, A.C., Pardal, M.A., 2008. Long-term effects of mercury in a salt marsh: hysteresis in the distribution of vegetation following recovery from contamination. Chemosphere 71, 765-772.

Wang, W.-X., Fisher, N.S., 1999. Assimilation efficiencies of chemical contaminants in aquatic invertebrates: a synthesis. Environmental Toxicology and Chemistry $18,2034-2045$.

Wilson, J.G., Elkaim, B., 1992. Estuarine bioindicators: a case for caution. Acta Oecologica $13,345-358$.

Wu, Y., Wang, W.X., 2011. Accumulation, subcellular distribution and toxicity of inorganic mercury and methylmercury in marine phytoplankton. Environmental Pollution 159 (10), 3097-3105.

Zar, J., 1996. Biostatistical Analysis, 3rd ed. Prentice-Hall, Upper Saddle River, NJ.

Zhou, Q., Zhang, J., Fu, J., Shi, J., Jiang, G., 2008. Biomonitoring: an appealing tool for assessment of metal pollution in the aquatic ecosystem. Analytica Chimica Acta 60 (6), 135-150 